\title{
Prenatal diagnosis of anterior sacral meningocele.
}

$\operatorname{AUTHOR}(S):$

Sumi, A; Sato, Y; Kakui, K; Tatsumi, K; Fujiwara, H; Konishi, I

\section{CITATION:}

Sumi, A ...[et al]. Prenatal diagnosis of anterior sacral meningocele.. Ultrasound in obstetrics \& gynecology 2011, 37(4): 493-496

\section{ISSUE DATE:}

2011-03-08

URL:

http://hdl.handle.net/2433/197587

\section{RIGHT:}

(c) 2011 ISUOG. Published by John Wiley \& Sons, Ltd.; This is the peer reviewed version of the following article: Sumi, A., Sato, Y., Kakui, K., Tatsumi, K., Fujiwara, H. and Konishi, I. (2011), Prenatal diagnosis of anterior sacral meningocele. Ultrasound Obstet Gynecol, 37: 493-496, which has been published in final form at http://dx.doi.org/10.1002/uog.8852; This is not the published version. Please cite only the published version.; この論文は出版社版でありません。引用の際 には出版社版をご確認ご利用ください。 
1 Prenatal diagnosis of anterior sacral meningocele

2

3 Akiko Sumi, Yukiyasu Sato*, Kazuyo Kakui, Keiji Tatsumi, Hiroshi Fujiwara, and Ikuo

4 Konishi

5

6 Department of Gynecology and Obstetrics, Kyoto University Graduate School of

7 Medicine

8

$9 \quad$ *Address correspondence and reprint requests to: Yukiyasu Sato, M.D., Ph.D.

10 Department of Gynecology and Obstetrics, Kyoto University Graduate School of

11 Medicine, Sakyo-ku, Kyoto 606-8507, Japan.

12 Tel; 81-75-751-3269: Fax; 81-75-761-3967: E-mail; yukiyasu@kuhp.kyoto-u.ac.jp

14 Short title; anterior sacral meningocele

15 Keywords; Currarino syndrome, cloacal anomaly, enteric duplication cyst,

16 hydrometrocolpos, MRI 
1 Abstract

2

3 Prenatal diagnosis of anterior sacral meningocele (ASM) is an extremely rare

4 condition and there has been only one English case report posted on the website.

5 A 36-year-old primigravida was referred for huge fetal pelvic cyst noted in routine

6 ultrasonography (USG) at $19^{+4}$ weeks' gestation. Neither fetal USG nor magnetic

7 resonance imaging (MRI) at $20^{+5}$ weeks' gestation could detect communication between

8 the cyst and the spinal cord. Since extension of the pear-shaped cyst through the

9 pelvic diaphragm down to the perineum was reminiscent of dilated vagina and uterine

10 cervix, tentative diagnosis of hydrometrocolpos secondary to imperforate hymen had

11 been considered.

12 In follow-up MRI at $33^{+5}$ weeks' gestation, narrow stalk connecting the pelvic cyst

13 and the spinal canal through the anterior sacral foramen was clearly delineated, allowing 14 us to reach the prenatal diagnosis of ASM. 
1 Case report

2

A 36-year-old nulligravida became pregnant after in vitro fertilization and embryo transfer. She was referred for huge fetal pelvic cyst noted in routine ultrasonography (USG) at $19^{+4}$ weeks' gestation.

Fetal USG at $20^{+5}$ weeks’ gestation showed pear-shaped pelvic cyst and bilateral hydronephrosis with normal amniotic volume (Figure 1A and 1B). Appearance of the external genitalia exhibited normal female phenotype. The pelvic cyst was located posterior to the bladder and extended down to the perineum. The size of the cyst was unchanged during the fetal urination, indicating that the cyst was not communicated with the bladder. Extrinsic ureteral compression by the cyst was considered to be a primary cause of bilateral hydronephrosis. Fetal magnetic resonance image (MRI) taken on the same day revealed that the pelvic cyst with multiloculated nature was located contiguous to the normal-appearing sacrum (Figure 1C). Differential diagnosis included cloacal anomaly, enteric duplication cyst, hydrometrocolpos secondary to imperforate hymen, and anterior sacral meningocele (ASM). Cloacal anomaly seemed unlikely due to lack of communication between the cyst and the bladder ${ }^{1}$. Enteric duplication cyst was implausible because the cyst had no peristaltic movement ${ }^{2}$. Communication of the cyst with spinal canal through sacral bony defect, which is characteristic of ASM, was not detected. Extension of pear-shaped cyst through the pelvic diaphragm down to the perineum was reminiscent of dilated vagina and uterine cervix ${ }^{3}$. Although multiloculated nature of the cyst could not be fully explained, tentative diagnosis of hydrometrocolpos secondary to imperforate hymen was considered.

Diameter of the renal pelvis was relatively constant and amniotic volume was preserved throughout the pregnancy, although the size of the pelvic cyst was gradually increased. The second MRI was taken at $33^{+5}$ weeks' gestation to reevaluate the diagnosis. In the T1-weighed image, the bowel containing hyperintense meconium signal was visualized separately from the cyst (Figure 2A). Narrow stalk connecting the pelvic cyst and the spinal canal through the anterior sacral foramen was clearly delineated in the T2-weighed image (Figure 2B and 2C). Accordingly, we reached the prenatal diagnosis of ASM. Additional meticulous USG search based on the MRI 
1 finding, however, failed to visualize the connecting stalk.

2 A female baby weighing 2530 g was vaginally born at $38^{+2}$ weeks' gestation with

3 normal Apgar score. Her left buttock was bulging with soft cystic mass palpable

4 beneath the skin. No abnormal neurological finding was noted. Postnatal MRI at 5

5 days old (Figure 3A) confirmed the communication between the pelvic cyst and the

6 subarachnoid space through left anterior sacral foramina (S3/4 and S4/5). Multilocular

$7 \quad$ cyst in the buttock region seemed distinct from the pelvic cyst. Helical computed

8 tomography at 51 days old (Figure 3B) revealed the defect in posterior aspect of the

9 vertebral bones below L3. The neonate thrived and remained asymptomatic except for

10 mild constipation. The operation was performed with posterior approach at 52 days

11 old. Since the posterior approach failed to identify the pedicle of the pelvic cyst, the

12 second operation was planned at 87 days old. Both the pelvic cyst and the buttock cyst

13 were successfully resected with abdominal and perineal approaches, respectively.

14 Histologically, the wall of the pelvic cyst was lined by ependymal cells and contained

15 fibrous stroma with neuronal tissue, indicating its meningeal origin. On the other hand,

16 the buttock cyst was composed of skin, fat, muscle, and mature neural tissue and was

17 diagnosed as mature cystic teratoma. 
Discussion

ASM is herniation of meningeal sac into the presacral retroperitoneal space through a congenital defect in the sacrum or through the widened anterior sacral foramina ${ }^{4}$. Prenatal diagnosis of ASM is an extremely rare condition and to our knowledge, there has been only one English case report posted on the website ${ }^{5}$.

Currarino syndrome is a unique complex of congenital caudal anomalies. These include anorectal malformation, sacral bony abnormality, and presacral mass (meningocele, teratoma, enteric duplication cyst, or any combination of these) ${ }^{6}$. Currarino et al. proposed incomplete separation of the neuroectoderm (future spinal cord) from the endoderm (future intestinal tract) as its possible embryonic etiology ${ }^{7}$. Half of the cases of Currarino syndrome are inherited ${ }^{7}$ and one or two features of the triad are commonly absent in the same family members, suggesting that this syndrome should be considered as a spectrum ${ }^{8}$. In this respect, the present case is considered to fall into the category of incomplete Currarino syndrome.

The age and the symptom at first presentation range widely in the patients with Currarino syndrome ${ }^{9}$. Associated anorectal malformation can cause bowel obstruction, leading to the early diagnosis in infancy ${ }^{10}$. In the absence of anorectal malformation, however, most of the patients remain asymptomatic until early adult life. These patients usually present with symptoms resulting from compression of surrounding tissue by enlarging presacral mass ${ }^{11}$ or acute meningitis ${ }^{12}$. Occasionally, the incidental discovery of a pelvic mass is the first presentation ${ }^{4}$. Thus, indication for surgical resection of asymptomatic ASM still remains to be determined.

When fetal presacral cyst is encountered, a variety of congenital anomalies including cloacal anomaly, enteric duplication cyst, hydrometrocolpos secondary to imperforate hymen, and ASM should be considered. Firstly, exclusion of cloacal anomaly, which is defined as a confluence of the rectum, vagina, and urethra into a single common channel, is of great importance because this anomaly usually requires intensive postnatal care with the worst outcome. For this purpose, one should evaluate possible communication between the cyst and the surrounding organs. USG is a suitable measure to see the communication with the bladder, because process of emptying the bladder into the cyst can be easily visualized ${ }^{1}$. In contrast, USG detection of 
1 communication with the bowel may be difficult. T1-weighed MRI can highlight the

2 meconium and visualization of meconium-containing bowel as a separate structure from

3 the cyst contributes to exclusion of cloacal anomaly ${ }^{13,14}$. Secondly, since aspiration of

4 meningeal cyst could induce chemical meningitis resulting in serious neurological

5 sequelae ${ }^{15}$, potential communication between the cyst and the spinal canal should be

6 meticulously evaluated. When the communicating stalk is too narrow for USG

7 detection as in the present case, MRI may be an essential tool for the prenatal diagnosis

8 of ASM.

9 
Reference

1. Warne S, Chitty LS and Wilcox DT. Prenatal diagnosis of cloacal anomalies. BJU Int 2002; 89: 78-81.

2. Richards DS, Langham MR and Anderson CD. The prenatal sonographic appearance of enteric duplication cysts. Ultrasound Obstet Gynecol 1996; 7: 17-20. 3. Adaletli I, Ozer H, Kurugoglu S, Emir H and Madazli R. Congenital imperforate hymen with hydrocolpos diagnosed using prenatal MRI. AJR Am J Roentgenol 2007; 189: W23-25. 4. Manson F, Comalli-Dillon K and Moriaux A. Anterior sacral meningocele: management in gynecological practice. Ultrasound Obstet Gynecol 2007; 30: 893-896. 5. $\quad$ thefetus.net: Kivilevitch Z: Anterior sacral meningocele. http://www.sonoworld.com/Client/Fetus/page.php?id=85 [Accessed 25 February 2010]. 6. Kirks DR, Merten DF, Filston HC and Oakes WJ. The Currarino triad: complex of anorectal malformation, sacral bony abnormality, and presacral mass. Pediatr Radiol 1984; 14: 220-225.

7. Currarino G, Coln D and Votteler T. Triad of anorectal, sacral, and presacral anomalies. AJR Am J Roentgenol 1981; 137: 395-398.

8. O'Riordain DS, O'Connell PR and Kirwan WO. Hereditary sacral agenesis with presacral mass and anorectal stenosis: the Currarino triad. Br J Surg 1991; 78: 536-538. 9. $\quad$ Lynch SA, Wang Y, Strachan T, Burn J and Lindsay S. Autosomal dominant sacral agenesis: Currarino syndrome. J Med Genet 2000; 37: 561-566. 10. Lee SC, Chun YS, Jung SE, Park KW and Kim WK. Currarino triad: anorectal malformation, sacral bony abnormality, and presacral mass--a review of 11 cases. $J$ Pediatr Surg 1997; 32: 58-61.

11. Krivokapic Z, Grubor N, Micev M and Colovic R. Anterior sacral meningocele with presacral cysts: report of a case. Dis Colon Rectum 2004; 47: 1965-1969. 12. Miletic D, Poljak I, Eskinja N, Valkovic P, Sestan B and Troselj-Vukic B. Giant anterior sacral meningocele presenting as bacterial meningitis in a previously healthy adult. Orthopedics 2008; 31: 182.

13. Dhombres F, Jouannic JM, Brodaty G, Bessiere B, Daffos F and Benifla JL. Contribution of prenatal imaging to the anatomical assessment of fetal hydrocolpos. Ultrasound Obstet Gynecol 2007; 30: 101-104. 14. Picone O, Laperelle J, Sonigo P, Levaillant JM, Frydman R and Senat MV. Fetal magnetic resonance imaging in the antenatal diagnosis and management of hydrocolpos. Ultrasound Obstet Gynecol 2007; 30: 105-109. 
1 15. Amacher AL, Drake CG and McLachlin AD. Anterior sacral meningocele.

2 Surg Gynecol Obstet 1968; 126: 986-994.

3

4 
1 Figure legend

2

3 Figure 1. Coronal (A) and horizontal (B) fetal ultrosonogram and sagittal T2-weighed

4 fetal magnetic resonance image (C) at 19 weeks' gestation.

5 A. Pear-shaped pelvic cyst (asterisk) is extended down to the perineum.

6 B. Pelvic cyst (asterisk) is located posterior to the bladder (arrowhead). Extrinsic

$7 \quad$ ureteral compression by the pelvic cyst causes left (L) and right (R) hydronephrosis.

8 C. Pelvic cyst with multiloculated nature (arrow) is contiguous to the sacrum.

Figure 2. Fetal magnetic resonances images (MRI) at 33 weeks’ gestation.

11 A. Coronal T1-weighed MRI. Bowel containing hyperintense meconium signal (black asterisk) is delineated as a separate structure from pelvic cyst (white asterisk).

B. Sagittal T2-weighed MRI. Narrow stalk (arrow) connects the pelvic cyst and the spinal canal through the anterior sacral foramen. Multilocular lesion (arrowhead) is located caudally to pelvic cyst.

C. Horizontal T2-weighed MRI. Narrow stalk (arrow) connects the pelvic cyst and the spinal canal through the left anterior sacral foramen.

Figure 3. T2-weighed magnetic resonances image at 5 days old (A) and helical computed tomography at 51 days old (B)

A. Huge pelvic cyst is connected with the spinal canal (arrow). Note that caudal multiloculated lesion (arrowhead) is distinct from the pelvic cyst.

B. Posterior aspect of the vertebral bones below L3 is defective. 


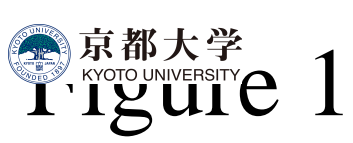
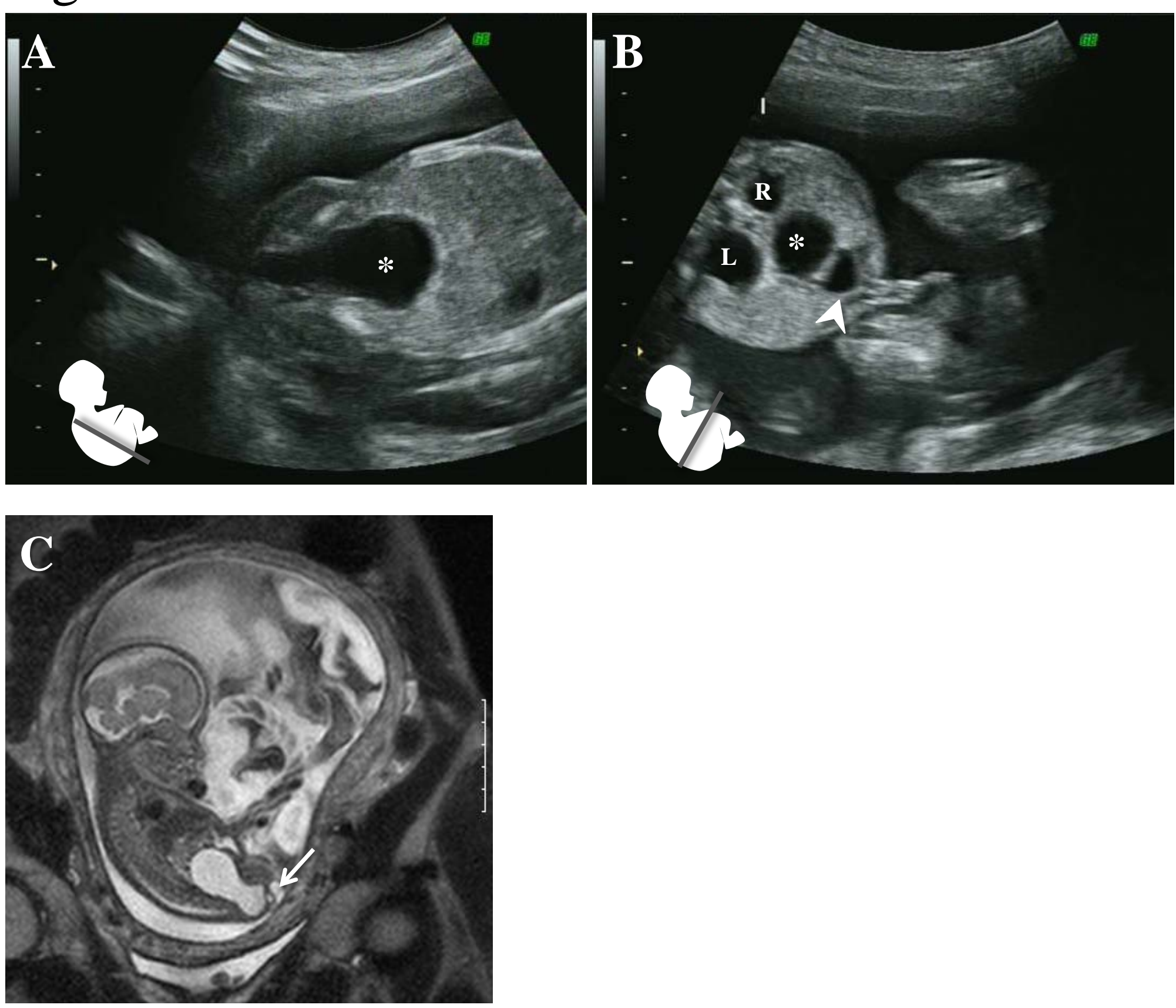

KURENAN II 


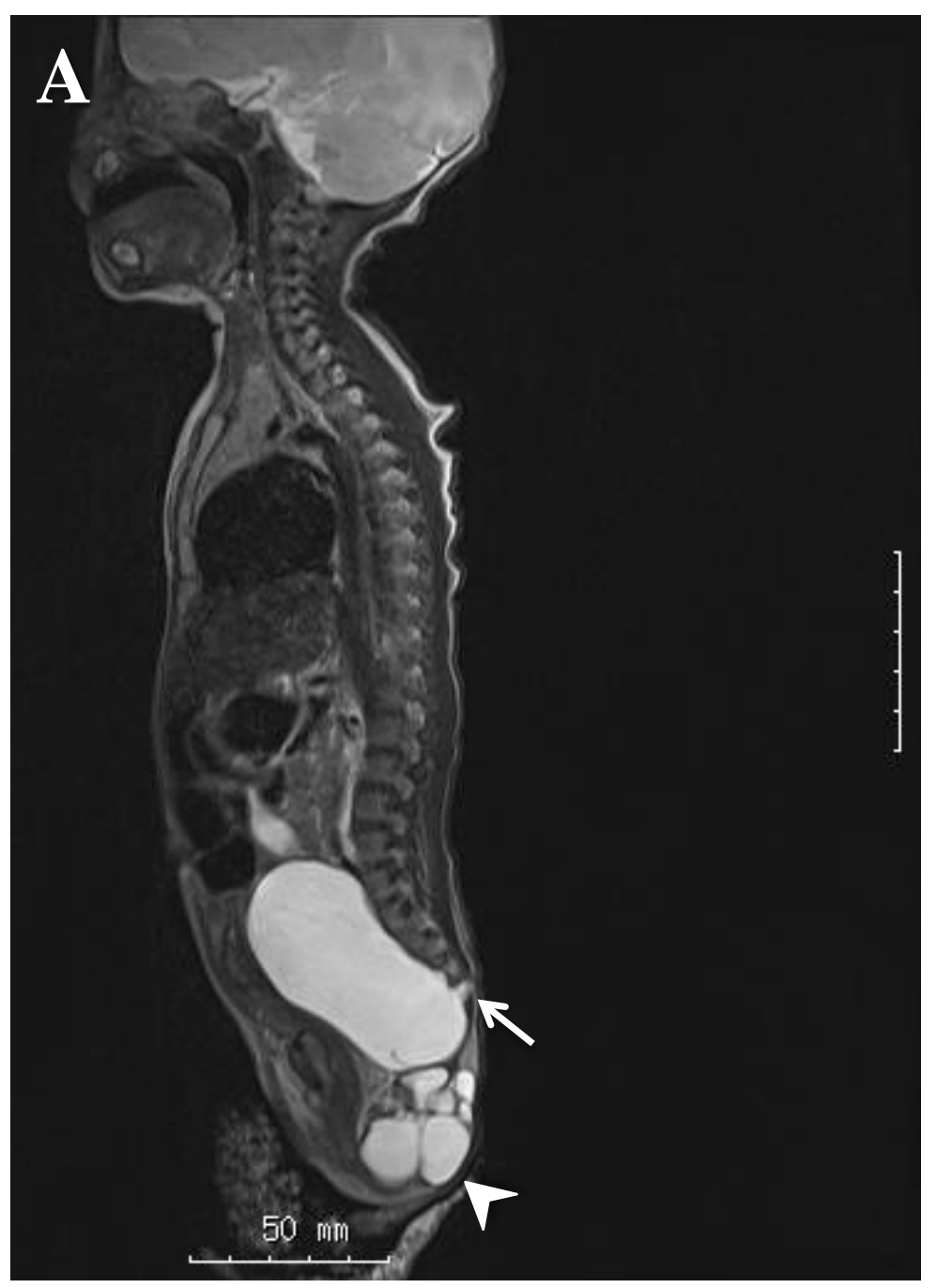

B

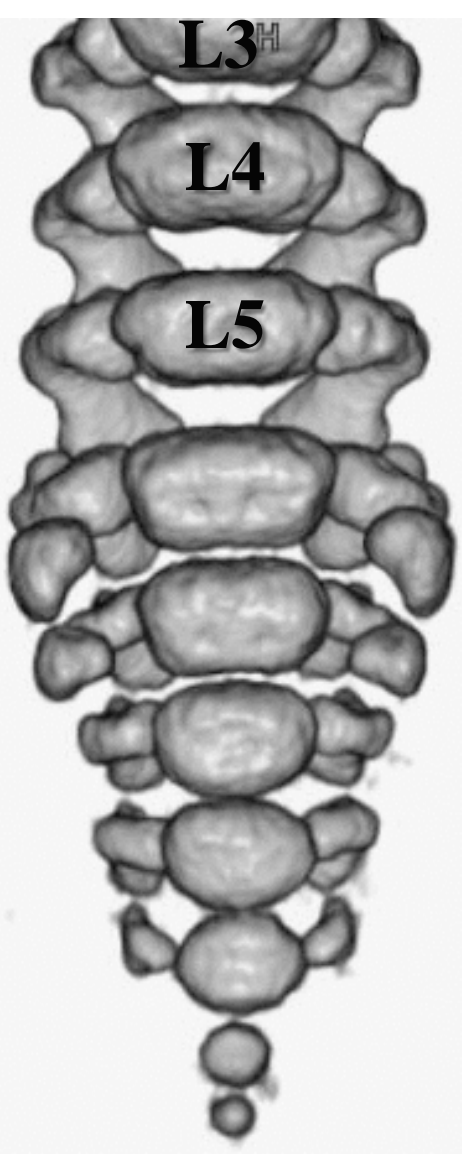

anterior aspect

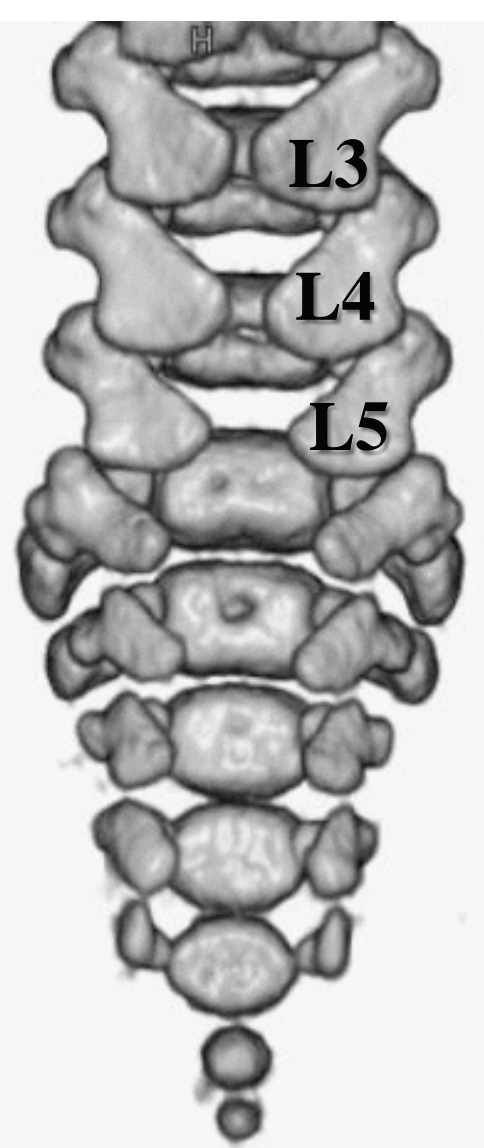

posterior aspect 